\title{
Breastfeeding and Development in Children Aged 5 Years
}

\author{
Adnan Bashir Bhatti ${ }^{1}$, Muhammad Usman ${ }^{2}$, Farhan Ali $^{3}$, Siddique Akbar Satti ${ }^{4}$ \\ Nabiyah Bakhtawar ${ }^{5}$ \\ ${ }^{1}$ Department of Medicine, Capital Development Authority (CDA) Hospital, Islamabad, Pakistan \\ ${ }^{2}$ Department of Medicine, Jinnah Hospital Lahore (JHL)/ Allama Iqbal Medical College (AIMC), Lahore, Pakistan \\ ${ }^{3}$ Department of Medicine, Capital Development Authority (CDA) Hospital, Islamabad, Pakistan \\ ${ }^{4}$ Department of Medicine, Capital Development Authority (CDA) Hospital, Islamabad, Pakistan \\ ${ }^{5}$ Department of Medicine, Jinnah Hospital Lahore (JHL)/ Allama Iqbal Medical College (AIMC), Lahore, Pakistan \\ dr.adnanbashir@gmail.com
}

Abstract

Background: Breastfeeding is the normal way of providing young infants with the nutrients they need for healthy growth and development. The WHO recommends exclusive breastfeeding for the first six months of life, after which infants should receive nutritionally adequate and safe complementary foods while breastfeeding continues up to two years of age or beyond. This research focuses on breastfeeding of children and its relationship to their motor and cognitive development.

Objective: To assess the development (motor and cognitive) in children aged 5 years who have been breastfed and who have been not.

Material and Methods

Study Design: Cross-sectional Study

Study Setting and duration: Duration of the study was 3 months.

Setting: Children visiting pediatric OPD of Capital Development Authority (CDA) Hospital, Islamabad, Pakistan. Inclusion criteria: We will select children aged 5 years whose mothers have given consent for the data collection

Data Collection and analysis: Data Analysis will be done using SPSS version 17.Initial Analysis will include frequency distribution and calculation of descriptive statistics e.g. mean median mode and standard deviation

Results: In our study we included 250 subjects following our inclusion criteria. Of 250 subjects 152 were male $60.80 \%$ and 98 were female $39.20 \%$ (Graph No. 1). Of these 250 children 83 (33.2\%) were school going and 167 (66.8\%) were not (Table No. 1).

We developed a scale to evaluate the motor and cognitive development of these subjects and found out that 10 ( $50 \%$ ) of the non-breastfed children fell in the Poor (score 1-4) category while only $1(0.4 \%)$ who was breastfed also fell in this category. Making a total of 11 (4.4\%) out of 250 subjects belonging to the Poor category. 7 (35 $\%$ ) of the non-breastfed children and 23 (10\%) of the breastfed children belonged to the Average (score 4-8) group. Making a total of 30 (12\%) out of 250 subjects belonging to the Average group. 3 (15\%) of the non-breastfed subjects and 206 (89.6\%) of the breastfed subjects fell in the Good (score 8-12) category. Making a total of 209 subjects out of 250 in the Good category. (Table No. 9)

Conclusions: Breast feeding has a strong relationship with the motor and cognitive development of the children.

Key words: Breastfeeding, Development, Growth 


\section{INTRODUCTION}

Breastfeeding is the normal way of providing young infants with the nutrients they need for healthy growth and development. The WHO recommends exclusive breastfeeding for the first six months of life, after which "infants should receive nutritionally adequate and safe complementary foods while breastfeeding continues up to two years of age or beyond. ${ }^{[1]} \mathrm{A}$ vast majority of mothers can and should breastfeed. Only under exceptional circumstances can a mother's milk be considered unsuitable for her infant. There are many factors which influence breastfeeding like mother's education, work status, health status and age. Highly educated, working and young aged mothers breastfeed for shorter durations. Also those women who give birth by c section are less likely to breastfeed. ${ }^{[2]}$ Breast milk is made from nutrients in the mother's bloodstream and bodily stores. Breast milk has just the right amount of fat, sugar, water, and protein that is needed for a baby's growth and development. ${ }^{[5]}$ The composition of breast milk changes depending on how long the baby nurses at each session, as well as on the age of the child.

Colostrum (also known as beestings or first milk) is a form of milk produced by the mammary glands in late pregnancy and the few days after giving birth. What colostrum lacks in volume it makes up for in power. Some people refer to colostrum as "high octane" milk. It's full of antibodies and immunoglobulins, which not only help protect newborns as they come into our world of bacteria and viruses, but also has a laxative effect that helps them expel the tarry first stools called meconium. ${ }^{[12]}$ The quality of a mother's breast milk may be compromised by smoking, alcoholic beverages, caffeinated drinks, marijuana, methamphetamine, heroin, and methadone. ${ }^{6]}$ Breastfeeding is a very personal decision. Many women have their own beliefs and feelings about whether or not they want to. "The American Academy of Pediatrics and the American Dietetic Associating promote breastfeeding as the BEST source of infant nutrition" Breastfeeding is a complete nutrition that is easy for the baby to digest, which promotes to the child eating more often due to faster digestion. It also helps in the jaw development of the baby because breastfeeding is more difficult; it helps strengthen the child's jaw. It also decreases allergies, decreases risk of diabetes and silica and decrease risk of SIDS. There are also controversial benefits of decreased risk for obesity in adulthood and improved cognitive development. ${ }^{[3]}$ Longer breastfeeding has also been associated with better mental health through childhood and into adolescence. ${ }^{[4]}$

Research shows that breastfeeding has significant health benefits for mothers. Breastfeeding assists the uterus return to its pre-pregnant state faster, can help women to lose weight after baby's birth, reduces the risk of ovarian cancer and pre-menopausal breast cancer, reduces the risk of osteoporosis and reduces the risk of mothers with gestational diabetes developing Type 2 diabetes. ${ }^{[13]}$

A substantial body of evidence suggests a benefit on cognitive development in infants as a result of breastfeeding. Several population studies have been conducted, the majority of which show a positive cognitive development in breastfed individuals. Not only breastfeeding but also the duration of breastfeeding has been reported to influence development in infants.Horwood LJ and Fergusson DM have shown that increasing duration of breastfeeding is associated with higher scores on measures of cognitive ability. ${ }^{[7]}$ Also, Pollock JI ${ }^{[8]}$ and PJ Quin ${ }^{[9]}$ have reported a positive relation between breastfeeding and cognitive development. But this positive association is not at all universal.

There are other researches too, which have been reported to show no association between breastfeeding and development. Silva et al ${ }^{[10]}$, Jacobson et al $^{[11]}$, Wigg et al ${ }^{[18]}$ have shown that the difference between breastfed and bottle-fed infants is not statistically significant in terms of development.Several studies have also been reported that show that a large number of social and parental education factors, that could reasonably be expected to influence child development independently, without the effect of breast feeding.

At the end of this research we will be able to point out the effect of breastfeeding on development; both motor and cognitive. 


\section{OBJECTIVES}

The objective of this study was to assess the development (motor and cognitive) in children aged 5 years who were breast fed and who were not breast fed.

\section{OPERATIONAL DEFINITION}

\section{Development}

Development is the gradual process of change and differentiation from a simple to a more advanced level of complexity. In humans the physical, mental, and emotional capacities that allow complex adaptation to the environment and function within society are acquired through growth, maturation, and learning. ${ }^{[14]}$

\section{Cognitive Development}

Cognitive development is the process of acquiring intelligence and increasingly advanced thought and problem-solving ability from infancy to adulthood. ${ }^{[15]}$

\section{Motor Development}

Motor development is the growth of muscular coordination in a child. ${ }^{[16]}$

\section{Breastfeeding}

Breastfeeding is the normal way of providing young infants with the nutrients they need for healthy growth and development. Exclusive breastfeeding is recommended up to 6 months of age, with continued breastfeeding along with appropriate complementary foods up to two years of age or beyond. ${ }^{[1]}$

\section{Material ANd Methods}

\section{Study Design}

It was a cross sectional study

\section{Study Setting}

The study was conducted in the Pediatric OPD of Capital Development Authority (CDA) Hospital, Islamabad.

\section{Duration of Study}

The duration of the study was three months i.e. 31 March, 2014 to $30^{\text {th }}$ June, 2014.

\section{Sample Size}

The sample size consisted of 250 children.

\section{Sampling Technique}

The sampling technique we used was non probability / purposive sampling.

\section{SAmple Selection}

\section{Inclusion Criteria}

We selected children aged 5 years whose mothers gave consent for the data collection.

\section{Exclusion criteria}

All children of the age less than 5 and more than 5 and whose mothers did not give consent for data collection were excluded from our research. 


\section{Data Collection Procedure}

250 children those selected their mothers were interviewed regarding history of breast feeding, cognitive motor development were assessed on a structured questionnaire and was scored as good average or poor and correlation was done with breast feeding.

\section{Data Analysis Procedure}

Data Analysis was done using SPSS version 17. Analysis includes frequency distribution and calculation of descriptive statistics e.g. means median mode and standard deviation.

\section{RESUlts ANd MAin FindingS}

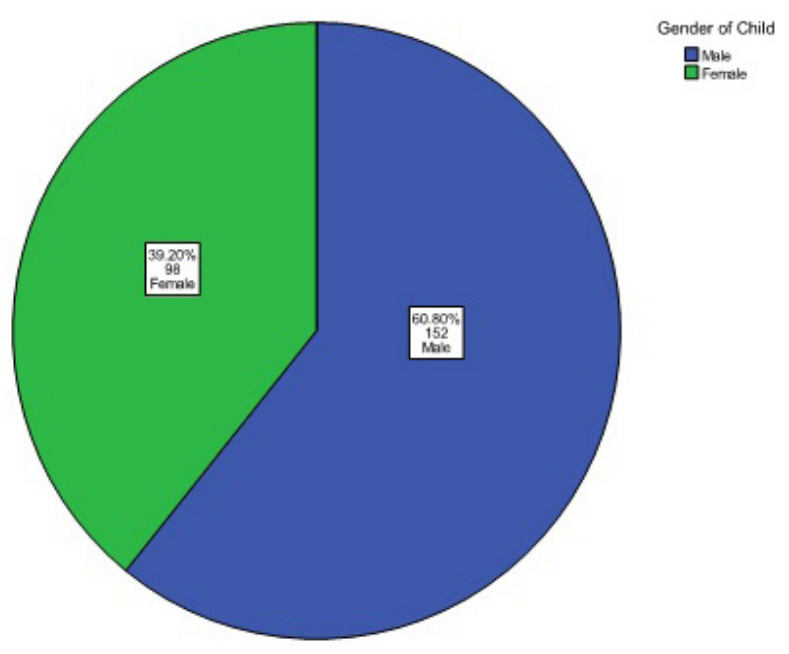

Graph1. Gender of Respondents

Table1. Schooling of Child

\begin{tabular}{|l|l|l|l|l|l|}
\hline & & Frequency & Percent & Valid Percent & Cumulative Percent \\
\hline \multirow{3}{*}{ Valid } & No & 167 & 66.8 & 66.8 & 66.8 \\
\cline { 2 - 6 } & Yes & 83 & 33.2 & 33.2 & 100.0 \\
\cline { 2 - 6 } & Total & 250 & 100.0 & 100.0 & \\
\hline
\end{tabular}

Table2. Statistics

\begin{tabular}{|l|l|l|l|l|}
\hline & & Age of Mother & Age of Father & Total family income \\
\hline \multirow{2}{*}{$\mathrm{N}$} & Valid & 250 & 250 & 250 \\
\cline { 2 - 5 } & Missing & 0 & 0 & 0 \\
\hline Mean & 31.06 & 36.90 & 40414.00 \\
\hline Median & 30.50 & 37.00 & 40000.00 \\
\hline Mode & 30 & 37 & 50000 \\
\hline Std. Deviation & 2.794 & 3.915 & 11560.284 \\
\hline Minimum & 24 & 29 & 10000 \\
\hline Maximum & 40 & 49 & 100000 \\
\hline
\end{tabular}




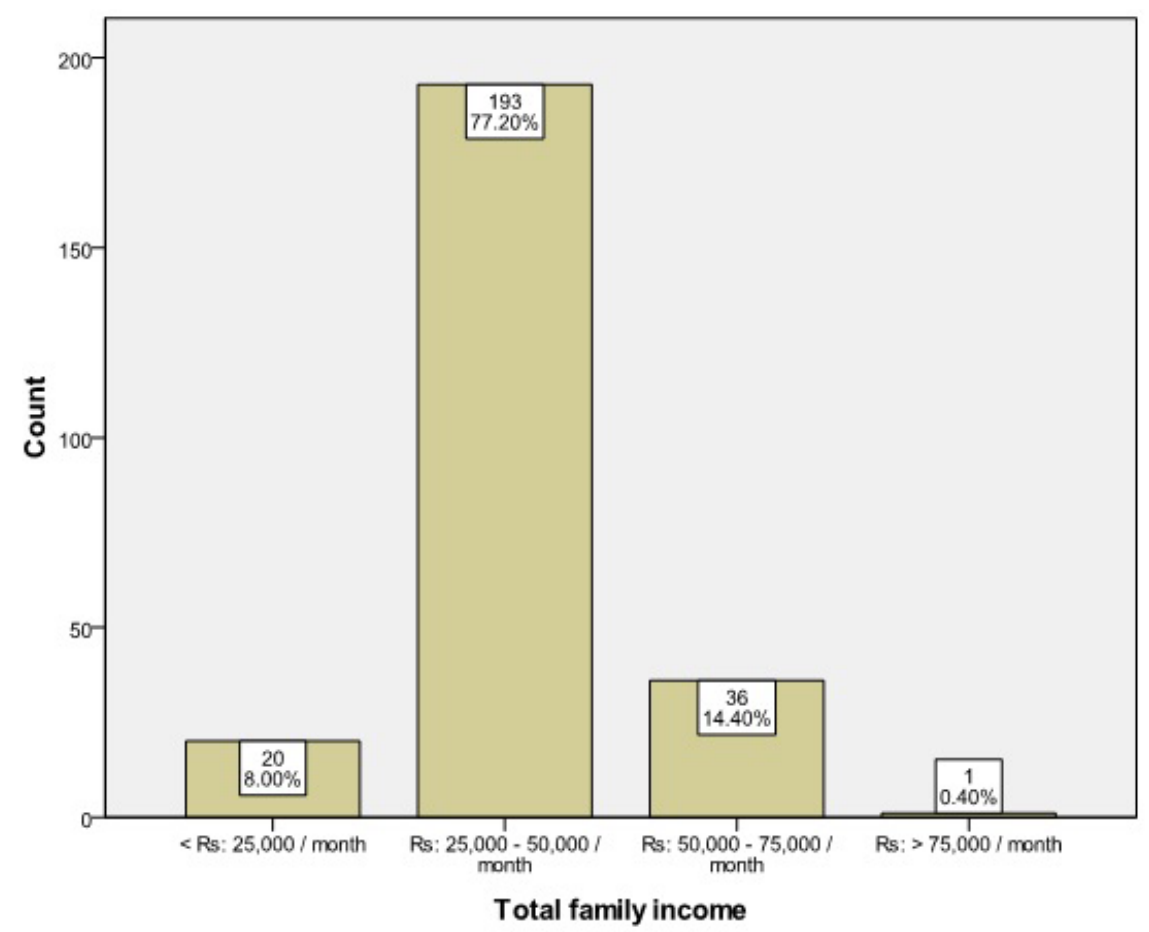

Graph2. Total Family Income

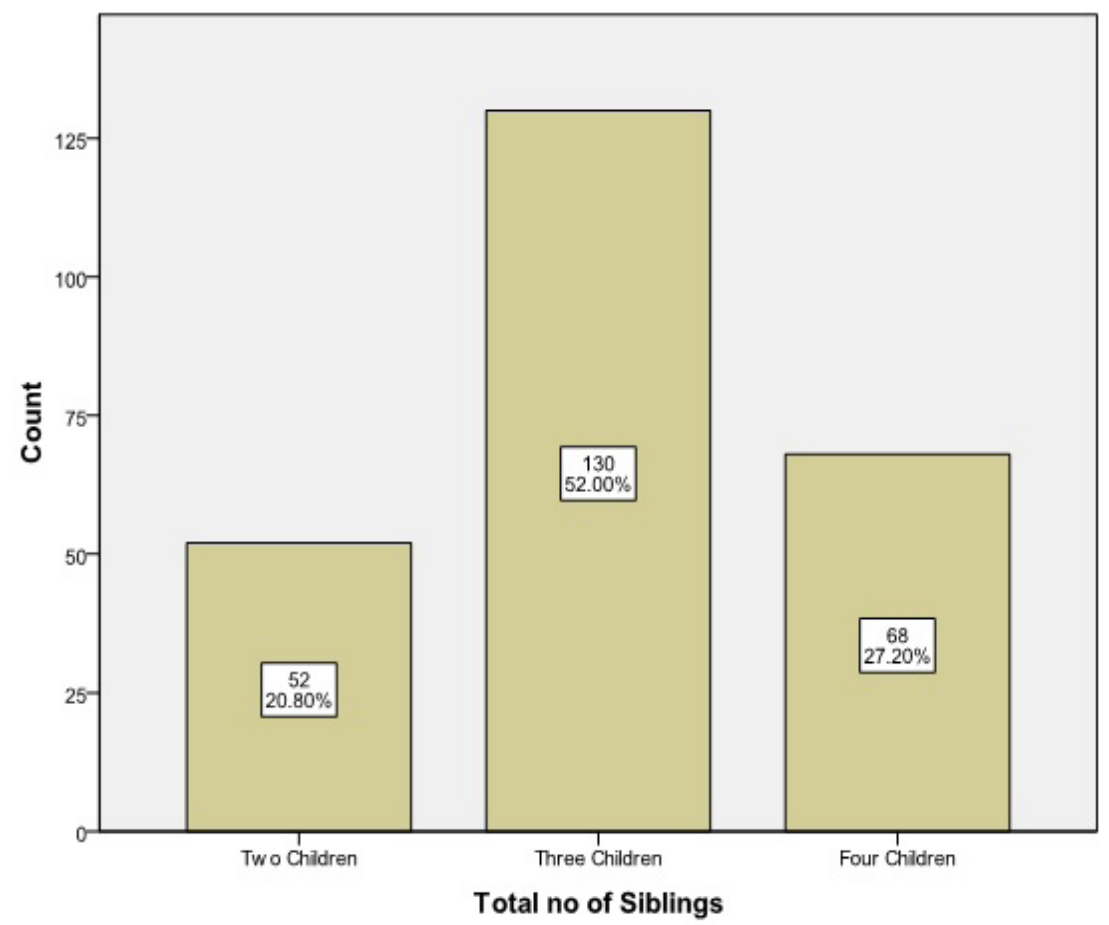

Graph3. Total no. of Siblings 
Breastfeeding and Development in Children Aged 5 Years

Table3. Breast feeding among Children

\begin{tabular}{|l|l|l|l|l|l|}
\hline & & \multicolumn{3}{|l|}{ Breast feeding to current Child } & Breast feeding to all children's \\
\hline & & Frequency & Percent & Frequency & Percent \\
\hline \multirow{3}{*}{ Valid } & No & 20 & 8.0 & 6 & 2.4 \\
\cline { 2 - 6 } & Yes & 230 & 92.0 & 244 & 97.6 \\
\cline { 2 - 6 } & Total & 250 & 100.0 & 250 & 100.0 \\
\hline
\end{tabular}

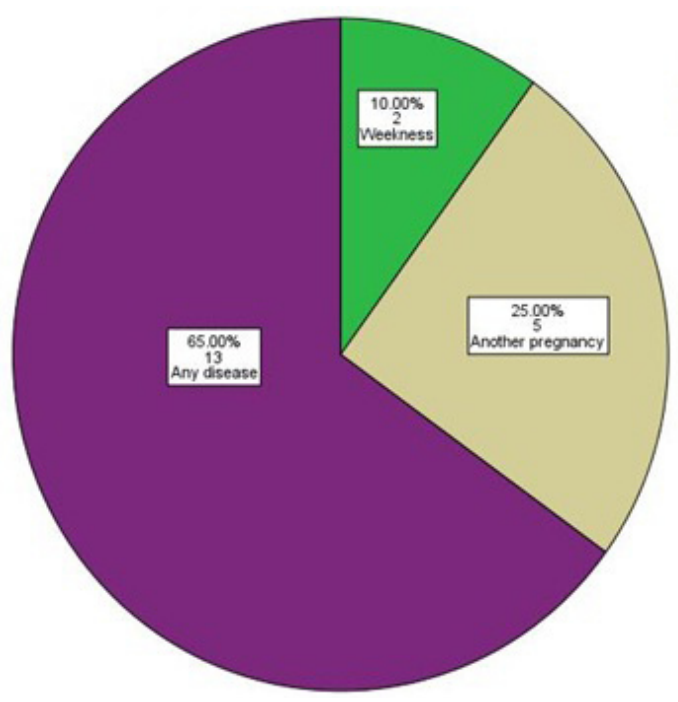

Reason for Non

口Weeiness

Another pregnanc

Any disease

Graph4. Duration of Breastfeeding

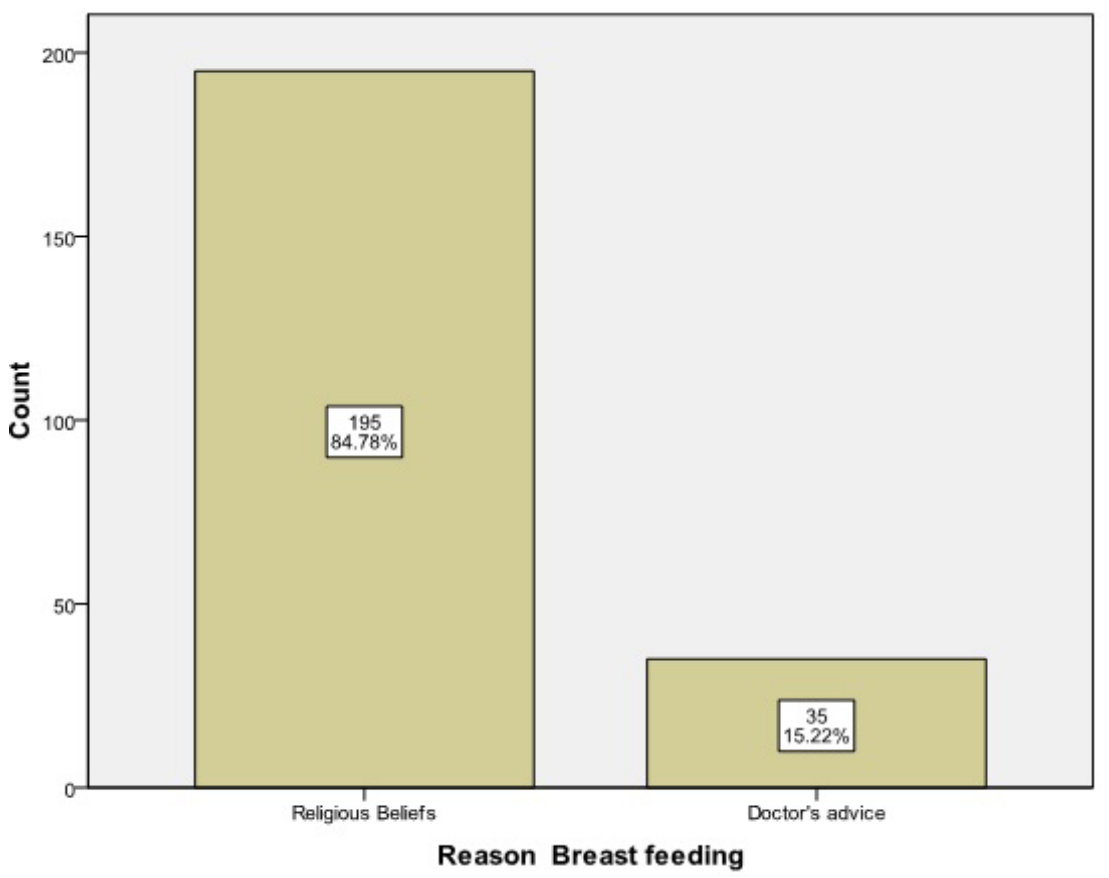

Graph5. Reason of Breastfeeding 


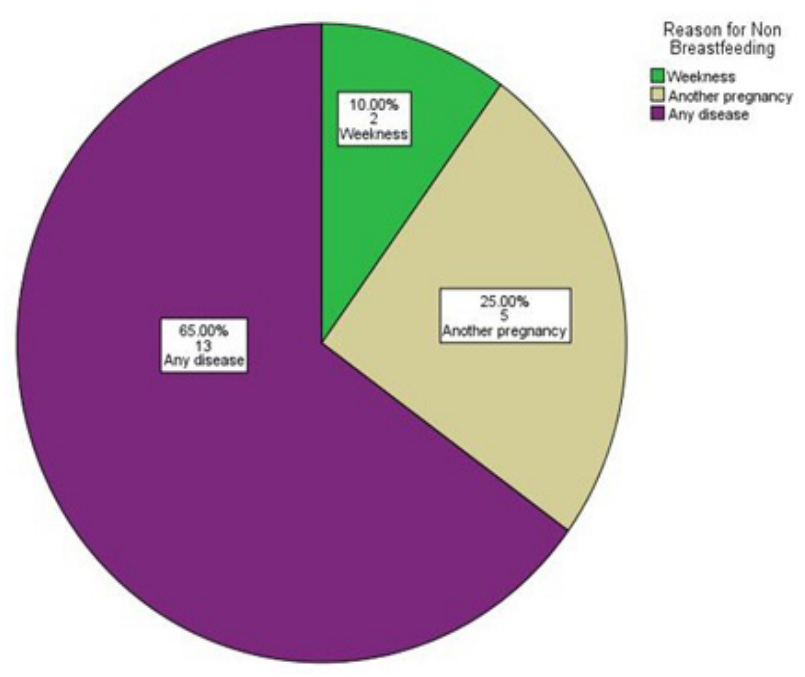

Graph6. Reason of Non-Breastfeeding

Table4. MothersPerception Frequencies (yes)

\begin{tabular}{|l|c|c|c|}
\hline & Responses & \multirow{2}{*}{ Percent of Cases } \\
\cline { 1 - 2 } & $\mathrm{N}$ & Percent & \\
\hline Role of Breastfeeding in development of child & 229 & $33.4 \%$ & $91.6 \%$ \\
\hline Benefits of breast feeding advised by doctor & 244 & $35.6 \%$ & $97.6 \%$ \\
\hline Consider breastfeeding for another child in future & 143 & $20.8 \%$ & $57.2 \%$ \\
\hline Formula Mild added with breastfeeding & 54 & $7.9 \%$ & $21.6 \%$ \\
\hline Bad Effect of bottle feeding on child development & 16 & $2.3 \%$ & $6.4 \%$ \\
\hline Total & 686 & $100.0 \%$ & $274.4 \%$ \\
\hline \multicolumn{2}{|c|}{ a. Dichotomy group tabulated at value 1 } \\
\hline
\end{tabular}

Table5. Mothers Perception and practices

\begin{tabular}{|c|c|c|c|}
\hline & \multicolumn{2}{|c|}{ Breast feeding to current Child } & \multirow[b]{2}{*}{ Total } \\
\hline & No & Yes & \\
\hline \multirow[t]{2}{*}{ Role of Breastfeeding in development of child } & 18 & 211 & 229 \\
\hline & $90.0 \%$ & $91.7 \%$ & \\
\hline \multirow[t]{2}{*}{ Benefits of breast feeding advised by doctor } & 20 & 224 & 244 \\
\hline & $100.0 \%$ & $97.4 \%$ & \\
\hline \multirow[t]{2}{*}{ Consider breastfeeding for another child in future } & 1 & 142 & 143 \\
\hline & $5.0 \%$ & $61.7 \%$ & \\
\hline \multirow[t]{2}{*}{ Formula Mild added with breastfeeding } & 5 & 49 & 54 \\
\hline & $25.0 \%$ & $21.3 \%$ & \\
\hline \multirow[t]{2}{*}{ Bad Effect of bottle feeding on child development } & 1 & 15 & 16 \\
\hline & $5.0 \%$ & $6.5 \%$ & \\
\hline Total & 20 & 230 & 250 \\
\hline
\end{tabular}


Breastfeeding and Development in Children Aged 5 Years

Table6. ChildDevelopment Frequencies

\begin{tabular}{|c|c|c|c|}
\hline & \multicolumn{2}{|c|}{ Responses } & \multirow{2}{*}{$\begin{array}{l}\text { Percent of } \\
\text { Cases }\end{array}$} \\
\hline & $\mathrm{N}$ & Percent & \\
\hline CS1:Count to five & 219 & $9.3 \%$ & $87.6 \%$ \\
\hline CS2: Knows address & 196 & $8.3 \%$ & $78.4 \%$ \\
\hline CS3: Can point to and name colors & 199 & $8.4 \%$ & $79.6 \%$ \\
\hline CS4: Can Match Commonly related objects & 193 & $8.2 \%$ & $77.2 \%$ \\
\hline CS5: Extended attention spasm & 177 & $7.5 \%$ & $70.8 \%$ \\
\hline CS6: Understanding of time & 172 & $7.3 \%$ & $68.8 \%$ \\
\hline FMS1: Cuts on a straight line & 182 & $7.7 \%$ & $72.8 \%$ \\
\hline FMS2: Can copy simple figures & 190 & $8.0 \%$ & $76.0 \%$ \\
\hline FMS3: Can type few capital letters & 209 & $8.8 \%$ & $83.6 \%$ \\
\hline GMS1: Can Jump forward as many as ten times without falling & 214 & $9.1 \%$ & $85.6 \%$ \\
\hline GSM2: Can Walk backwards in a line & 204 & $8.6 \%$ & $81.6 \%$ \\
\hline GSM3: Can Swing a bat & 208 & $8.8 \%$ & $83.2 \%$ \\
\hline Total & 2363 & $100.0 \%$ & $945.2 \%$ \\
\hline
\end{tabular}

Table7. Child Development Indices

\begin{tabular}{|c|c|c|c|c|}
\hline & & \multicolumn{2}{|c|}{ Breast feeding to current Child } & \multirow[b]{2}{*}{ Total } \\
\hline & & No & Yes & \\
\hline \multirow{2}{*}{\multicolumn{2}{|c|}{ CS1:Count to five }} & 13 & 206 & 219 \\
\hline & & $65.0 \%$ & $89.6 \%$ & \\
\hline \multirow{2}{*}{\multicolumn{2}{|c|}{ CS2: Knows address }} & 7 & 189 & 196 \\
\hline & & $35.0 \%$ & $82.2 \%$ & \\
\hline \multirow{2}{*}{\multicolumn{2}{|c|}{ CS3: Can point to and name colors }} & 11 & 188 & 199 \\
\hline & & $55.0 \%$ & $81.7 \%$ & \\
\hline \multirow{2}{*}{\multicolumn{2}{|c|}{ CS4: Can Match Commonly related objects }} & 11 & 182 & 193 \\
\hline & & $55.0 \%$ & $79.1 \%$ & \\
\hline \multirow{2}{*}{\multicolumn{2}{|c|}{ CS5: Extended attention spasm }} & 9 & 168 & 177 \\
\hline & & $45.0 \%$ & $73.0 \%$ & \\
\hline \multirow{2}{*}{\multicolumn{2}{|c|}{ CS6: Understanding of time }} & 8 & 164 & 172 \\
\hline & & $40.0 \%$ & $71.3 \%$ & \\
\hline \multirow{2}{*}{\multicolumn{2}{|c|}{ FMS1: Cuts on a straight line }} & 9 & 173 & 182 \\
\hline & & $45.0 \%$ & $75.2 \%$ & \\
\hline \multirow{2}{*}{\multicolumn{2}{|c|}{ FMS2: Can copy simple figures }} & 6 & 184 & 190 \\
\hline & & $30.0 \%$ & $80.0 \%$ & \\
\hline \multirow{2}{*}{\multicolumn{2}{|c|}{ FMS3: Can type few capital letters }} & 10 & 199 & 209 \\
\hline & & $50.0 \%$ & $86.5 \%$ & \\
\hline \multirow{2}{*}{\multicolumn{2}{|c|}{$\begin{array}{l}\text { GMS1: Can Jump forward as many as ten } \\
\text { times without falling }\end{array}$}} & 11 & 203 & 214 \\
\hline & & $55.0 \%$ & $88.3 \%$ & \\
\hline \multirow{2}{*}{\multicolumn{2}{|c|}{ GSM2: Can Walk backwards in a line }} & 13 & 191 & 204 \\
\hline & & $65.0 \%$ & $83.0 \%$ & \\
\hline \multirow{2}{*}{\multicolumn{2}{|c|}{ GSM3: Can Swing a bat }} & 4 & 204 & 208 \\
\hline & & $20.0 \%$ & $88.7 \%$ & \\
\hline \multicolumn{2}{|l|}{ Total } & 20 & 230 & 250 \\
\hline
\end{tabular}


Breastfeeding and Development in Children Aged 5 Years

Table8. Statistics

\begin{tabular}{|l|l|l|}
\hline \multicolumn{2}{|l|}{ TotalScore } & \multicolumn{2}{|l|}{} \\
\hline \multirow{2}{*}{ Valid } & 250 \\
\cline { 2 - 3 } & Missing & 0 \\
\hline Mean & 9.4520 \\
\hline Median & 10.0000 \\
\hline Mode & 10.00 \\
\hline Std. Deviation & 1.80575 \\
\hline Minimum & 2.00 \\
\hline Maximum & 12.00 \\
\hline
\end{tabular}

Histogram

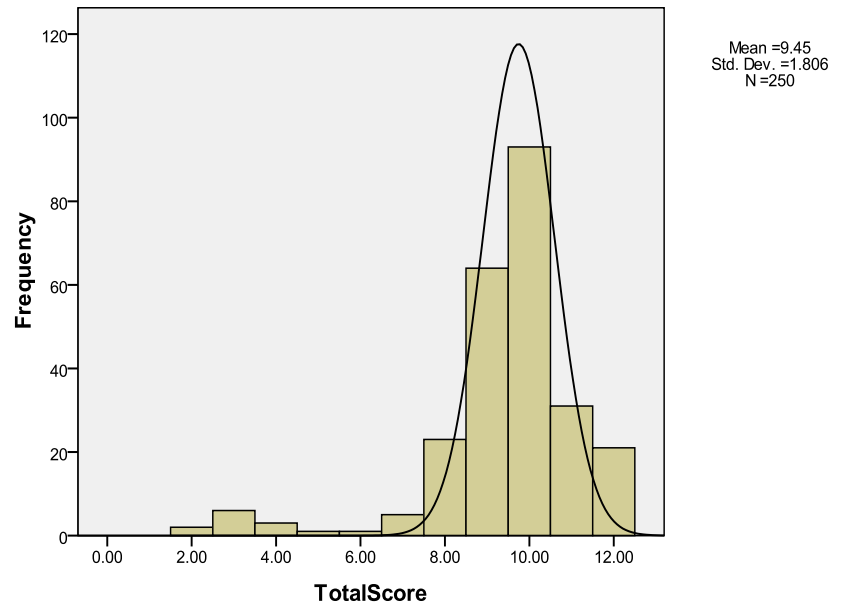

Graph7. Histogram

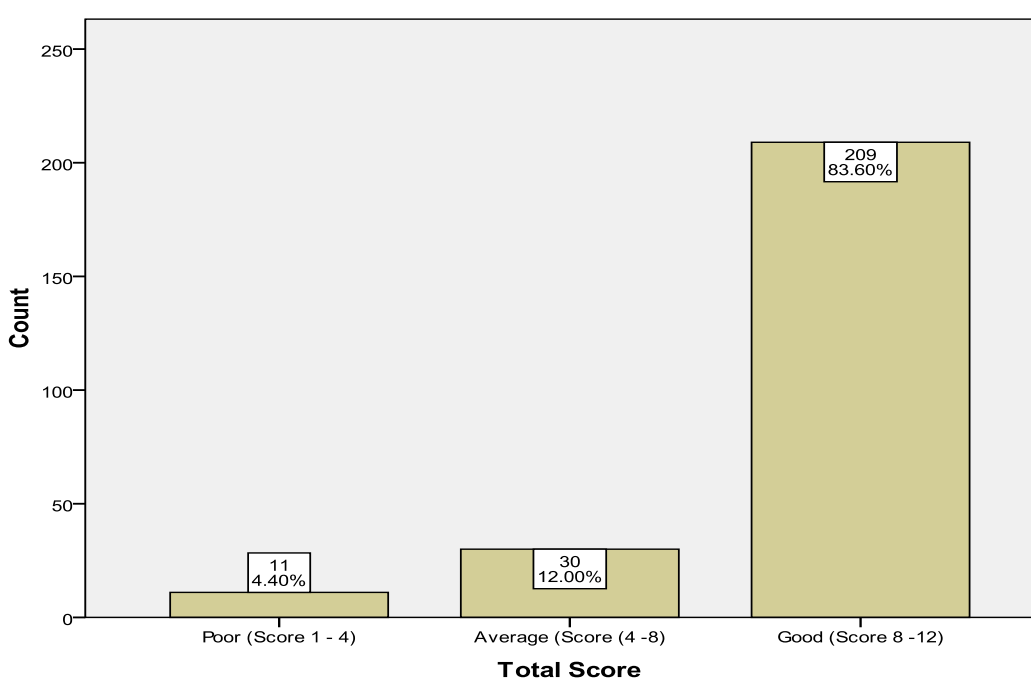

Graph8. Total Score 
Breastfeeding and Development in Children Aged 5 Years

Table9. Total Score * Breast feeding to current Child Cross tabulation

\begin{tabular}{|c|c|c|c|c|c|}
\hline & & & \multicolumn{2}{|c|}{$\begin{array}{l}\text { Breast feeding to current } \\
\text { Child }\end{array}$} & \multirow[b]{2}{*}{ Total } \\
\hline & & & No & Yes & \\
\hline \multirow[t]{6}{*}{ Total Score } & \multirow[t]{2}{*}{ Poor (Score 1 - 4) } & Count & 10 & 1 & 11 \\
\hline & & $\begin{array}{l}\% \text { within Breast feeding } \\
\text { to current Child }\end{array}$ & $50.0 \%$ & $.4 \%$ & $4.4 \%$ \\
\hline & \multirow[t]{2}{*}{ Average (Score (4 -8) } & Count & 7 & 23 & 30 \\
\hline & & $\begin{array}{l}\% \text { within Breast feeding } \\
\text { to current Child }\end{array}$ & $35.0 \%$ & $10.0 \%$ & $12.0 \%$ \\
\hline & \multirow[t]{2}{*}{ Good (Score 8 -12) } & Count & 3 & 206 & 209 \\
\hline & & $\begin{array}{l}\% \text { within Breast feeding } \\
\text { to current Child }\end{array}$ & $15.0 \%$ & $89.6 \%$ & $83.6 \%$ \\
\hline \multirow[t]{2}{*}{ Total } & & Count & 20 & 230 & 250 \\
\hline & & $\begin{array}{l}\% \text { within Breast feeding } \\
\text { to current Child }\end{array}$ & $100.0 \%$ & $100.0 \%$ & $100.0 \%$ \\
\hline
\end{tabular}

Table10. Chi-Square Test

\begin{tabular}{|l|l|l|l|}
\hline \multicolumn{4}{|c|}{ Chi-Square Tests } \\
\hline & Value & df & Asymp. Sig. (2-sided) \\
\hline Pearson Chi-Square & $124.556^{\mathrm{a}}$ & 2 & .000 \\
\hline & & & \\
\hline
\end{tabular}

\section{RESULTS}

In our study we included 250 subjects following our inclusion criteria. Of 250 subjects 152 were male $60.80 \%$ and 98 were female $39.20 \%$ (Graph No. 1). Of these 250 children 83 (33.2\%) were school going and 167 (66.8\%) were not (Table No. 1). The mean age of mother was 31.06 years and that of father was 36.90 , the median was 30.50 and 37.00 respectively. Mode of age of mothers was 30 and that of fathers was 37, while Standard Deviation was 2.794 and 3.915 respectively. The mean total family income was Rs.40414.00, the median of the income was 40000, mode was 50000 and Standard Deviation was 11560.284 (Table No. 2). The income of 20 families (8\%) was less than Rs 25000/month, of 193 families (77.20\%) was between Rs.25000 - 50000 per month, of 36 families (14.40\%) was between Rs.50000 - 75000 per month while only one family (0.40\%) had an income higher than Rs.75000 (Graph No. 2). 52 (20.80\%) subjects had 2 siblings, 130 (52.00\%) had 3 siblings and $68(27.20 \%)$ had 4 (Graph No. 3).

Out of 250 subjects 230 (92.0\%) were breastfed while 20 (8.0\%) were not. 244 (97.6\%) families had all their children breastfed while 6 (2.4\%) families had not (Table No. 3). 164 (65.60\%) subjects out of the 250 in our study were breastfed up to 24 months while $66(26.40 \%)$ were breastfed up to 12 months and $20(8 \%)$ subjects were not breastfed (Graph No. 4). 195 (84.78 \%) subjects stated that the reason of breastfeeding were their religious beliefs while 35 (15.22 \%) stated the reason to be the doctor's advice (Graph No. 5 ). 13 (65.00\%) subjects were not breastfed because of some disease, 5 (25.00\%) were not breastfed because of another pregnancy and the mothers of 2 (10\%) subjects were too weak to breastfeed (Graph No. 6).

$11(4.40 \%)$ subjects had a total score between 1-4, 30 (12.00\%) had a score of 4-8, while 209 (83.60\%) had a score between 8-12. Score of 1-4 was considered poor, score of 4-8 was considered average and 8-12 


\section{Breastfeeding and Development in Children Aged 5 Years}

was considered a good score. This scoring system was based on the tests we performed on the subjects that analyzed the motor and cognitive development of subjects. A total of 12 such tests were performed, each having a score of 1 (Graph No. 8).

$10(50 \%)$ of the non-breastfed children fell in the Poor (score $1-4)$ category while only $1(0.4 \%)$ who was breastfed also fell in this category. Making a total of 11 (4.4\%) out of 250 subjects belonging to the Poor category. 7 (35\%) of the non-breastfed children and $23(10 \%)$ of the breastfed children belonged to the Average (score 4-8) group. Making a total of 30 (12\%) out of 250 subjects belonging to the Average group. 3 (15\%) of the non-breastfed subjects and 206 (89.6\%) of the breastfed subjects fell in the Good (score 8-12) category. Making a total of 209 subjects out of 250 in the Good category. (Table No. 9). Cognitive and motor skills assessed were compared among breast fed and non breast fed and was analyzed using Chi-square. There was a statistical significant relationship between cognitive and motor skill socre and breastfeeding. $($ Chi-square $=124.556, \mathrm{P}<.000)$

\section{DiscusSON}

New studies solidifies the connection between breast-feeding and intelligence, but it's not the only way that mom can influence youngsters' IQ, even before birth.

While previous studies have drawn a link between breastfeeding and cognition, and even extended an association to higher social status, it's never been absolutely clear whether the connection was due to the breast milk or to the bond that the practice builds between mom and child, which can itself enhance brain development. Or, for that matter, whether it was mom's (and dad's) own education and social status that filtered through in their parenting that contributed to their children's IQ.

But researchers from Boston Children's Hospital, reporting in JAMA Pediatrics, say they have conducted the most comprehensive study to date to flesh out how much breast feeding influences brain development in youngsters. They teased away as many factors known to contribute to intelligence as possible, such as mother's IQ, parental income and education, and whether the toddlers spent time in child care outside of the home. They also collected detailed information from 1,312 babies and mothers on how long the moms breast fed their babies, whether the infants were exclusively breastfed, and how much fish the mothers consumed, since omega- 3 fatty acids found in some fish are also present in breast milk and known to influence brain development.

In our study Out of 250 subjects 230 (92.0\%) were breastfed while 20 (8.0\%) were not.

10 (50\%) of the non-breastfed children fell in the Poor (score 1-4) category while only 1 (0.4 \%) who was breastfed also fell in this category. Making a total of 11 (4.4\%) out of 250 subjects belonging to the Poor category. $7(35 \%)$ of the non-breastfed children and $23(10 \%)$ of the breastfed children belonged to the Average (score 4-8) group. Making a total of 30 (12\%) out of 250 subjects belonging to the Average group. 3 (15\%) of the non-breastfed subjects and 206 (89.6\%) of the breastfed subjects fell in the Good (score 8-12) category. Making a total of 209 subjects out of 250 in the Good category.

The longer the mothers breastfed, the more likely their children were to score higher on vocabulary tests at age 3 and on intelligence tests at age 7. Breastfeeding during a child's first year of life could boost their IQ by about four points when they enter school.

Among the most consistently reported benefits of breastfeeding in developed country settings have been higher results on IQ tests and other measures of cognitive development among children and adults who had been breastfed compared with those who were formula-fed. A meta-analysis by Anderson et al1999 reported consistent IQ differences favoring breastfed over formula-fed infants, with most differences in the 2- to 5-point range $^{19}$. Most of the studies included in the meta-analysis were observational in design and were carried out in subjects who were born healthy and at term, although a larger difference of 8 points was reported by Lucas et al 
in follow-up of a randomized trial in preterm infants ${ }^{20}$. Several of these studies demonstrated a clear dose-response relationship, with larger differences associated with longer durations of breastfeeding. With 1 recent notable exception, studies published since the meta-analysis have been entirely consistent with these results and conclusions ${ }^{21,22}$.

Despite the robustness of the reported findings, many observers remain unconvinced about the cognitive benefits of breastfeeding ${ }^{23-24}$. As mentioned earlier, the evidence is based almost entirely on observational studies. The beneficial effect of breastfeeding is unlikely to be explained by the higher socioeconomic status of breastfeeding mothers because most studies have controlled statistically for socioeconomic differences. Some of the studies have even controlled for maternal IQ with most studies reporting an attenuated but persistent and significant effect. ${ }^{25}$ On the other hand, the benefits are likely to be confounded by other, more subtle differences in the mother's behavior or her interaction with the infant. These differences are extremely difficult to measure and virtually impossible to control for in observational studies.

Our study showed that $89.6 \%$ ) of the breastfed subjects fell in the Good (score 8-12) category. Making a total of 209 subjects out of 250 in the Good category.

The solution to these methodological problems is a randomized controlled trial, but randomization to breastfeeding vs artificial feeding is infeasible and probably unethical. It is, however, both feasible and ethical to randomize the participants to a breastfeeding promotion intervention. One strategy would be to promote breastfeeding initiation, but most women decide whether to breastfeed early in or even before pregnancy and such a strategy is therefore difficult with regard to both timing and logistics. An alternative and more feasible strategy is to promote breastfeeding exclusivity and duration among those mothers who have already decided to initiate breastfeeding, with analysis by intention to treat. This is the strategy we used in the Promotion of Breastfeeding Intervention Trial (PROBIT), a cluster-randomized trial in the Republic of Belarus. ${ }^{27}$ In this article, we describe measures of cognitive development among children enrolled in this trial and followed up at age 6.5 years.

\section{CONCLUSION}

Breastfeeding has a strong relationship with the development of children.Children who are breastfed for an appropriately long duration show better cognitive and motor skill development. Children who are not breastfed or are breastfed for a shorter duration for any reason show poor cognitive and motor development. In third world countries like Pakistan, where the education of mothers is still inadequate, much emphasis should be put on improving breastfeeding status.

\section{REFERENCES}

1. WHO. Definition of breastfeeding. Cited 2014 Apr 02. Available from URL: http://www.who.int/topics/ breastfeeding/en/

2. Hwang WJ, Chung WJ, Kang DR, Suh MH.Factors affecting breastfeeding rate and duration.J Prev Med Public Health. 2014 Apr 02;39(1):74-80.

3. Samour, P. Q., \& King, K. (Eds.). (2012). Pediatric Nutrition (4th ed.). London, United Kingdom: Jones \& Baretless Learning. 2014 Apr 02.

4. Oddy WH, Kendall GE, Li J, et al. (2010). "The long-term effects of breastfeeding on child and adolescent mental health: a pregnancy cohort study followed for 14 years". J. Pediatr.156 (4): 568-74.

5. "Mothers and Children Benefit from Breastfeeding". Womenshealth.gov. 27 February 2009. Archived from the original on 16 Mar 2009[cited 2014 Apr 02]. Available from: http://en.wikipedia.org/wiki/ Breastfeeding\#cite_note-25 
6. Fisher D (November 2006). "Social drugs and breastfeeding". Queensland, Australia: Health e-Learning. Available from : http://en.wikipedia.org/wiki/Breastfeeding\#cite_note-25

7. Horwood L, Fergusson D. Breastfeeding and Later Cognitive and Academic Outcomes. 1998; 101 (1): e9-e9.

8. Pollock JI. Long-term associations with infant feeding in a clinically advantaged population of babies. Dev. Med. Child Neurol. 1994; 36: 429-40.

9. Quinn P, O'callaghan M, Williams G, Najman J, Anderson M, Bor W. The Effect Of Breastfeeding On Child. [e-book] 5th ed.; 2001.

10. SILVA P, BUCKFIELD P, SPEARS G. Some Maternal and Child Developmental Characteristics Associated with Breast Feeding: A Report from the Dunedin Multidisciplinary Child Development Study. 1978; 14 (4): 265-268. Available from:

11. Jacobson SW, Chiodo LM, Jacobson JL. Breastfeeding effects on intelligence quotient in 4- and 11-year-old children. Pediatrics 1999; 103.

12. Barger J. Babycenter, L.L.C. cited on 2014 Apr 02.

13. Queensland health. Queensland health; 2011[2011 jan 19 [cited 2014 Apr 04]. Available from : http:// www.health.qld.gov.au/breastfeeding/importance.asp)

14. Mosby's Medical Dictionary. definition of development[internet]. 8th edition. (C) 2009, Elsevier.[cited 2014 Apr 04]. Available from: http://medical-dictionary.thefreedictionary.com/development

15. Dictionary.com.cognitive development In: The American Heritage ${ }^{\circledR}$ New Dictionary of Cultural Literacy[internet]. 3rd ed. Source location: Houghton Mifflin Company, 2005[cited 2014 Apr 04]. Available: http://dictionary.reference.com

16. Dictionary.com.motordevelopment In:TheAmericanHeritage ${ }^{\circledR} N e w$ Dictionary ofCultural Literacy[internet]. 3rd ed: Houghton Mifflin Company; 2005[cited 2014 Apr 04].Available: http://dictionary.reference.com

17. Study design 101[internet].[place unknown]: Himmelfarb Health Sciences Library; 2009 nov[cited 2014 Apr 03]. Availble from: (http://www.gwumc.edu/library/tutorials/studydesign101/casecontrols.html)

18. Wigg NR, Tong S, McMichael AJ, Baghurst PA, Vimpani G, Roberts R. Does breast feeding at six months predict cognitive development. Aus. N.Z. J. Pub. Health 1998; 22: 232-6.

19. Anderson JW, Johnstone BM, Remley DT. Breast-feeding and cognitive development: a meta-analysis. Am J ClinNutr 1999;70 (4) 525- 535 PubMed

20. Lucas AMorley RCole TJLister GLeeson-Payne C. Breast milk and subsequent intelligence quotient in children born preterm. Lancet 1992;339 (8788) 261- 264.

21. Der GBatty GDDeary IJ Effect of breast feeding on intelligence in children: prospective study, sibling pairs analysis, and meta-analysis [published online ahead of print October 4, 2006]. BMJ 2006;333 (7575) 945 PubMed10.1136/bmj.38978.699583.55

22. Jacobson SWChiodo LMJacobson JL Breastfeeding effects on intelligence quotient in 4- and 11-year-old children. Pediatrics 1999;103 (5) e71 PubMed10.1542/peds.103.5.e71

23. Angelsen NKVik TJacobsen GBakketeig LS Breast feeding and cognitive development at age 1 and 5 years. Arch Dis Child 2001;85 (3) 183- 188 PubMed

24. Mortensen ELMichaelsen KFSanders SAReinisch JM The association between duration of breastfeeding and adult intelligence. JAMA 2002;287 (18) 2365- 2371. 
25. Oddy WHKendall GEBlair Ede Klerk NHStanley FJLandau LISilburn SZubrick S Breast feeding and cognitive development in childhood: a prospective birth cohort study. PaediatrPerinatEpidemiol 2003;17 (1) 81- 90 Gómez-Sanchiz MCañete RRodero IBaeza JEAvila O Influence of breast-feeding on mental and psychomotor development. ClinPediatr (Phila) 2003;42 (1) 35- 42

26. Lawlor DANajman JMBatty DO'Callaghan MJWilliams GMBor W Early life predictors of childhood intelligence: findings from the Mater-University study of pregnancy and its outcomes. PaediatrPerinatEpidemiol 2006;20 (2) $148-162$

27. Drane DLLogemann JA A critical evaluation of the evidence on the association between type of infant feeding and cognitive development. PaediatrPerinatEpidemiol 2000;14 (4) 349- 356

\section{QUESTIONNAIRE}

\section{Co-relation of Breastfeeding with Development (Motor and Cognitive) in children aged 5 years}

Name of Child: Age (years): Gender:M / F

School going:

(YES / NO)

Name of mother: Age (years):

Religion:

Name of Father: Age (years):

Job:

No. of siblings:

Address:

Monthly income (PRs.):

- Have you breastfed all your children?

(YES / NO)

- Have you breastfed the child under research? (YES / NO) If NO state reason

- For how long have you breastfed (in months): stopping

- If you did breastfeed please state your reason for doing so?
1) Family pressure
2) Religious belief
3) Doctors advice

- If you chose not to breastfeed please state your reason for doing so?
1) Weakness
2)Another pregnancy
2) Any disease (specify)
4) Any medication (specify)

- Do you think breastfeeding plays any role in the development of child? DON'T KNOW)

- Did the Doctor tell you about the benefits of breastfeeding? (YES / NO)

- If you had another child would you consider breastfeeding? (YES / NO / Don't know)

- Have you fed your child with formula milk along with breastfeeding? (YES/NO)

- What do you think are the effects of bottle feeding on child's development?
1) Good (please specify)
2) Bad (please specify)
2) No effect
4) Don't know 
Breastfeeding and Development in Children Aged 5 Years

\begin{tabular}{|c|cl|}
\hline \multicolumn{1}{|c|}{ SKILLS } & & \multicolumn{1}{c|}{ ACTIVITIES } \\
\hline Cognitive Skills & $\circ$ & Counts to five. \\
& $\circ$ & Knows street and town where he/she lives. \\
& $\circ$ & Points to and names six colors. \\
& $\circ$ & Matches commonly related objects. \\
& $\circ$ & Has extended attention span. \\
\hline Fine Motor Skills & $\circ$ & Has increased understanding of time. \\
\hline Gross Motor Skills & $\circ$ & Cuts on a straight line. \\
& $\circ$ & Copies simple figures. \\
& $\circ$ & Types a few capital letters. \\
\hline & $\circ$ & Jumps forward as many as ten times without falling. \\
& $\circ$ & Walks backward in a line, heel to toe. \\
& $\circ$ & Can swing at a stationary ball with a bat. \\
\hline
\end{tabular}

Citation: Adnan Bashir Bhatti, Muhammad Usman, Farhan Ali, Siddique Akbar Satti, Nabiyah Bakhtawar. “Breastfeeding and Development in Children Aged 5 Years". American Research Journal of Gynaecology, 1(1): 49-63.

Copyright (C) Adnan Bashir Bhatti, Muhammad Usman, Farhan Ali, Siddique Akbar Satti, Nabiyah Bakhtawar. This is an open access article distributed under the Creative Commons Attribution License, which permits unrestricted use, distribution, and reproduction in any medium, provided the original work is properly cited. 